IJ§ER

ISSN: 2149-5939
International Journal of Social Sciences and Education Research

Online, http://dergipark.gov.tr/ijsser

Volume: 3(2), 2017

\title{
Basketbolculara terabant ile uygulanan kuvvet antrenmanlarının motorik beceriler ve şut performansı üzerine etkisi
}

The effect of strength trainings by using theraband on the motor skills and shooting performance of basketball players

Umut Canl ${ }^{1}$

Received Date: 02 / 02 / 2017

Accepted Date: 01 / $06 / 2017$

$\ddot{O} z$

Çalışmamızın amacı 9 hafta boyunca uygulanan terabant antrenmanlarının basketbolcuların şut performanslarına ve bazı biyomotorik becerilerine etkisinin incelenmesidir. Yaş ortalaması 12,79 yll, spor yaşı ortalaması 3,32 yıl olan altyapı yerel liglerinde müsabakalara katılan 14 erkek basketbolcu çalışmamıza gönüllü olarak katılmıştır. Çalışmaya katılan basketbolcular ön test verilerine göre 7 'şer kişilik kontrol ve çalışma gruplarına ayrılmıştır. 9 hafta süresince hem kontrol hem de çalışma grubuna haftada ortalama 3,09 basketbol antrenmanı yaptırllırken, çalışma grubuna ilaveten basketbol antrenmanı ile birleștirilmiş terabant kullanılarak kuvvet antrenmanı yaptırılmıştır. Sonuç olarak, 13 yaş içerisinde bulunan erkek basketbolcularda, terabant ile yaptırllan kuvvet antrenmanlarının bazı biyomotorik becerilerin gelişimine katkı sağladığı, terabant çalışmalarının sezon içerisinde kuvvet gelişimi açısından etkin bir şekilde uygulanabileceği düşünülmektedir.

Anahtar sözcükler: Basketbol, terabant, motorik özellik

\begin{abstract}
The aim of this study is to examine the effects of theraband trainings which has been applied for 9 weeks on the shooting performance and some biomotor skills of the basketball players. During the 9-week period, an average of 3.09 basketball training sessions have been performed each week with both the control and the study groups. In addition, the study group has performed strength trainings using theraband combined with basketball training. As a result, it is observed that the strength trainings by using theraband contribute to the development of some biomotor skills in male basketball players who are at the age of 13.
\end{abstract}

Keywords: Basketball, theraband, motoric feature

\section{Giriş}

Ülkemizde çevresel ve toplumsal kültür yapılarının değişmesine paralel olarak ailelerin çocuklarını spora yönlendirmesinde popüler sporları tercih ettikleri gözlenmektedir. Spor çocuğun çok yönlü gelişmesinde ve sosyalleşmesinde önemli rol oynadığ için, erken yaşlarda spora başlaması tavsiye edilmektedir (Muratl1, 1998).

Ülkemizde giderek yaygınlaşan ve taraftar kitlesi kazanan spor branşlarının başında basketbol gelmektedir. Özellikle ulusal takımımızın ve son yıllarda kulüp takımlarımızın elde ettiği başarılar neticesinde basketbol branşı taraftar kitlesini arttırarak popüler spor dalları arasında yerini almıştır. Basketbol kuvvet, sürat, dayanıklılık, hareketlilik ve koordinasyon gibi temel motorik

\footnotetext{
${ }^{1}$ Dr., Milli Eğitim Bakanlığı, Tekirdağ/TÜRKIYYE, umutcanli@hotmail.com
} 
Canlı, U. (2017). Basketbolculara terabant ile uygulanan kuvvet antrenmanlarının motorik beceriler ve şut performans1 üzerine etkisi. International Journal of Social Sciences and Education Research, 3(3), 857-869.

özelliklerin tümünün bir arada olmasını gerektiren bir spor dalıdır (Canlı, 2017). Tüm spor dallarında olduğu gibi basketbolda da temel motorik özelliklerin geliştirilmesi uygulanan antrenmanların vazgeçilmez bir bölümünü oluşturur. Sportif başarının temelinde, temel motorik özelliklerin geliştirilmesi ön şartlardan birisidir. Bunun da en önemli bölümünü kuvvet ve kuvvet antrenmanı oluşturur (Sevim, 1988).

Kuvvet, temel biyomotorik yeteneklerden birisidir ve her spor branşı için olmazsa olmaz bir değere sahiptir (Acar, 2000). Çocuklarda kuvvet özelliğini geliştirmek için hangi antrenman yöntemi seçilirse seçilsin bazı önemli noktalar vardır. Bunların en başında antrenörlerin bu konu hakkında uzman olması ve antrenmanlarda sürekli çocukların doğru tekniği uygulayıp uygulamadığını kontrol etmesi gerekmektedir. Bir diğer önemli nokta ise çok iyi tasarlanmış bir antrenman programıdır. İyi düzenlenmiş bir adaptasyon programının ardından çocukların uygulayabileceği yükler seçilmeli ve program başından sonuna kadar takip edilmelidir (Zatsiorsky ve Kraemer, 2006).

Kuvveti geliştirmenin bir takım yöntemleri vardır. Bu yöntemler kendi vücut ağırlığının yanında değişik ekipmanlar ve makinelerle sağlanmaktadır. Kuvveti geliştirmek için kullanılan bu araçlardan birisi de elastik kuvvet bantlarıdır (terabant). Elastik bantların en büyük özelliği uzadıkça dirençlerinin artmasıdır. Maliyetlerinin ucuzluğu ve taşınabilir olması nedeniyle antrenörler bu bantları tercih etmektedirler. Ayrıca bu bantlar birçok amaç için de kullanılmaktadır. Sporcuların sakatlandıktan sonra rehabilitasyon antrenmanlarında da kullanımı çok yaygındır (Page ve Ellenbecker, 2005).

Çocuklarda terabant kullanımı ile kuvvet gelişimini amaçlayan çalışmalarda, düzenli yapılan terabant egzersizleri ile çocuklarda kuvvet gelişimi olduğu belirlenmiştir (Yolcu, 2010). Terabantlar kuvvet gelişimine katkı sağladığı gibi, diğer motorik özelliklerin gelişimine de katkı sağlayabilirler. Çünkü terabantlar çok yönlü hareket ve uygulanan hareketi her açıda hissetme özelliklerine sahiptirler. Ayrıca her yaş grubunda kullanılabilir olmaları da terabantların diğer bir avantajidır (Page ve Ellenbecker, 2005).

Çalı̧̧mamızda adölesan dönem içerisinde bulunan basketbolculara terabant kullanılarak yaptırılan kuvvet antrenmanlarının şut performanslarına ve bazı biyomotorik becerilerine etkisinin incelenmesi amaçlanmıştır.

\section{Yöntem}

\subsection{Araştırma grubu}

Araştırmanın örneklemini yaş ortalaması 12,79 yıl, spor yaşı ortalaması 3,32 yıl olan altyapı yerel liglerinde müsabakalara katılan 14 erkek basketbolcu oluşturmaktadır. Araştırmaya katılan basketbolcular ön test verilerine göre 7'şer kişilik kontrol ve çalışma gruplarına ayrılmıştır. 9 hafta süresince hem kontrol hem de çalışma grubuna haftada ortalama 3,09 basketbol antrenmanı yaptırılırken, çalışma grubuna ilaveten basketbol antrenmanı ile birleştirilmiş terabant kullanılarak kuvvet antrenmanı yaptırılmıştır.

\subsection{Verilerin toplanmasl}

\subsubsection{Boy Uzunluğu ve vücut ağırlı̆ğ ölçümü}


Canl, U. (2017). The effect of strength trainings by using theraband on the motor skills and shooting performance of basketball players. International Journal of Social Sciences and Education Research, 3(3), 857-869.

Boy uzunluğu ölçümlerinde duvara monte edilmiş hassaslık derecesi $0,1 \mathrm{~cm}$ olan stadiometre kullanıldı. Ölçümler katılımcıların ayakları çıplak durumda, vücut ağırlıkları iki ayağına eşit dağıtılmış, topuklar birleşik ve stadiometreye temasta, baş frankfort planında, kollar omuzlardan serbestçe yanlara sarkıtılmış durumdayken alındı. Katılımcıların vücut ağılıkları, hassaslık derecesi 0,1 kg olan elektronik baskül cihazıyla çıplak ayak ve sadece şort, tişört kalacak şekilde ölçüldü. Elde edilen değerler kg cinsinden kaydedildi (Özer, 2009).

\subsubsection{Biyomotorik ölçümler}

Dikey sıçrama testi: Testin yapılması için $200 \mathrm{~cm}$ uzunluğunda, $60 \mathrm{~cm}$ genişliğinde beyaz bir tahta yerden $155 \mathrm{~cm}$ yükseklikte olacak şekilde duvara monte edildi. Katılımcıdan ilk önce ayakta kolunu uzatarak uzanabileceği en üst noktaya dokunması daha sonra sıçrayarak ulaşabildiği en üst noktaya dokunması istendi. Katılımcının ayakta uzanabildiği yükseklik ile sıçrayarak dokunabildiği nokta arasındaki mesafe $\mathrm{cm}$ cinsinden ölçüldü. Bu test dinleme aralıklarıyla üç kez tekrarlandı ve en iyi derece skor olarak kaydedildi. Testin başlangıcından önce katılımcılara ısınma ve esneme çalışmaları yaptırıldı (Kamar, 2008).

Esneklik testi: Esneklik ölçümünde otur-uzan testi kullanıldı. Katılımcılar yere oturarak ve çıplak ayak tabanını düz bir şekilde test sehpasına dayayıp, gövdesi ileri doğru eğilerek, dizler bükülmeden eller vücudun önünde olacak şekilde uzanabildiği kadar öne doğru uzanarak cetveli yavaşça ileri itmeye çalıştı. Test yapan kişi, katılımcının yanında durarak deneğin dizlerini bükülmesini engelledi. Katılımc1, en uzak noktada öne ya da geriye esnemeden 1-2 sn. bekledi. Test iki defa tekrar edildi ve en yüksek değer kaydedildi (Tamer, 2000)

Flamingo denge testi: Katılımcı, denge aletinin üzerine tercih ettiği ayağı ile çıkarak diğer ayağını dizinden büküp, kalçasına doğru çekerek ve aynı taraftaki eli ile tutarak dengede durmaya çalıştı. Denge bozulduğunda (ayağını tutarken bırakırsa, tahtadan yere düşerse, vücudunun herhangi bir bölgesiyle yere dokunursa ve benzeri) süre durduruldu. Katılımcı, denge aletine çıkarak dengesini tekrar sağladığında, süre kaldığı yerden devam etti. Bir dakika süreyle test bu şekilde devam etti. Süre tamamlandığında, katılımcının her denge sağlama girişimi (düştükten sonra) sayıldı ve bu sayı test bitiminde bir dakika süre tamamlandığında, katılımcının puanı olarak kaydedildi (Kamar, 2008).

30 saniye şınav testi: Katılımcıların 30 sn şınav testi için 1/1000 hassasiyetli el kronometresi kullanıldı. Katılımcı yerde bulunan cimnastik minderi üzerinde, kollar omuz genişliğinde açık, dirsekler gergin, dizler yere temas etmeyecek ve bel bölgesi de aşağ sarkmayacak biçimde başlangıç pozisyonu aldı. Başla komutu ile birlikte sporcu gövdesini 90 derece zemine yaklaştırdı ve tekrar başlangıç pozisyonuna döndü. Bu şekilde test 30 saniye boyunca devam ettirildi ve test süresinin bitiminde katılımcının elde ettiği değer test skoru olarak bilgi formuna kaydedildi (Mackenzie, 2005).

30 saniye mekik testi: Katılımcıların 30 sn. mekik testi için 1/1000 hassasiyetli el kronometresi kullanıldı. Katılımcılara, sırt üstü yatar durumda, dizler 900 bükülü, eller ensede ve ayak tabanları yere temasta iken başla komutuyla 30 saniye süreyle tekrar edebildikleri kadar mekik yaptırıldı. Mekik çekme esnasında ayakların yerden temasının kesilmemesi için ayaklar tutuldu ve test başlamadan önce her katılımcıya bir deneme yaptırıldı. Katılımcıların yere yattıklarında omuzlarının yere, doğrulduklarında ise dirseklerinin dizlerine değmesine dikkat edildi, 30 saniye içerisinde tekrar edebildiği mekik sayısı bilgi formuna kaydedildi (Pekel, 2007). 
Canlı, U. (2017). Basketbolculara terabant ile uygulanan kuvvet antrenmanlarının motorik beceriler ve şut performans1 üzerine etkisi. International Journal of Social Sciences and Education Research, 3(3), 857-869.

30 m. sürat testi: Deneklerin ölçülü zeminde çıkış noktasında, işaret ile birlikte, maksimal hız ile 30 m koşmaları, başlangıç ve bitiş arasındaki sürenin 1/1000 hassasiyetli el kronometresi yardımıyla tespit edilmesi sonucu test gerçekleştirildi. Test iki kez tekrar edildi ve en iyi değer sn. cinsinden ölçüm formuna kaydedildi. Testin başlangıcından önce deneklere ısınma ve esneme egzersizleri yaptırıldı.

Sağlık topu atış testi: Katılımcı 2 kg ağırlığındaki sağlık topunu, baş üstünden her iki eliyle birlikte, durduğu yerden mümkün olduğu kadar uzağa atmaya çalıştı. Katılımcı başlama çizgisinin hemen gerisinde ve bir adımı olmak üzere pozisyonunu aldı. Atış esnasında koşmasına izin verilmedi. Katılımcı gövdesini geriye doğru bükerek, atış için gerekli ivmeyi temin edebildi. Test skoru, atı̧ mesafesinin metre ve santimetre cinsinden kaydedildi. Yapılan iki deneme sonunda elde edilen iyi skor kaydedildi (Kamar, 2008).

Durarak uzun atlama testi: Katılımcının ayak parmak uçları başlama çizgisinin gerisinde yerini aldı ve deneğin dizlerini, kollarını, belini bükmesine izin verildi. Komutla birlikte denek, kol çekerek başlama çizgisinden ileri doğru mümkün olduğu kadar uzağa atlamaya çalıştı. Başlama çizgisiyle katılımcının bu çizgiye en yakın topuğu arasındaki mesafe katılımcının skoru olarak kaydedildi. Katılımcı iki deneme yaptı ve denemelerden en iyi skora sahip olan derece deneğin uzun atlama skoru olarak kaydedildi (Kamar, 2008).

\subsection{3.Şut performans testi}

Teste başlamadan önce katılımcılara 10 dakika topla birlikte çalışarak genel ısınma, 7 dakika dinamik esneme ve 12 dakika özel şut drilleri içeren 1sınma protokolü uygulandı. Katılımcılar çemberin orta noktasından zemine iz düşüm olarak belirlenen noktadan 5 metre uzaklıkta olacak şekilde 2 köşe, 2 forvet bölgesi ve tepe bölgesine gelecek şekilde 5 huni yerleştirildi. Gruplar 3 katılımcıdan oluşturuldu. Katılımcılardan biri şut atarken diğer 2 katılımcı topları yakalayıp, şut atan katılımcıya pas verdi. Katılımcılar sağ köşeden başlayarak her bölgeden 2 atış yaparak toplamda 1 sette 10 atış yaptılar. 3 setten oluşan teste setler arasında 3 dakika dinlenme verildi. Şut atış esnasında zaman sınırlaması uygulanmadı (Pojskic, Separovic ve Uzicanin, 2011).

\subsection{Verilerin Analizi}

Verilerin normal dağılıma uygun olup olmadığının belirlenmesi için Shapiro-Wilk Testi kullanıldı. Grup içi istatistiklerde paired-samples $t$ testi, gruplar arası istatistiklerde ise independentsamples $t$ testi kullanıldı. Normallik testi ve diğer istatistiksel analizler 0,05 anlamlılık düzeyinde yapild1.

\subsection{Antrenman programı}

Araştırmaya katılan basketbolcular ön test verilerine göre 7'şer kişilik kontrol ve çalışma gruplarına ayrılmıştır. Kontrol grubu 90 dakika süren (25 dakika genel ısınma ve esneme çalışmaları - 25 dakika teknik geliştirici ve düzeltici çalışmalar - 30 dakika teknik ve taktiksel çalışmalar - 10 dakika soğumaya yönelik çalışmalar) basketbol antrenmanı yaparken, çalışma grubu (25 dakika genel ısınma ve esnetme çalışmaları - 25 terabant ile kuvvet çalışması- 30 dakika teknik ve taktiksel çalışmalar- 10 dakika soğumaya yönelik çalışmalar) basketbol antrenmanı ve kuvvet çalışması yapmıştır. Kuvvet antrenmanının planlanmasında basketbolcuların terabant ile kuvvet çalışmalarına uyumu ve adaptasyonu için ilk 4 haftalık periyotta hafif dirençteki terabantlar ile (3 set10 tekrar, 1-2 dakika dinlenme) 8 hareketten oluşan büyük kas gruplarının aktif olduğu kuvvet çalışması uygulandı. Son 5 haftalık periyotta terabant direnç seviyesi arttırılıp yine büyük kas 
Canl, U. (2017). The effect of strength trainings by using theraband on the motor skills and shooting performance of basketball players. International Journal of Social Sciences and Education Research, 3(3), 857-869.

gruplarının aktif olduğu bazı hareketlerin değiştiği 8 hareketten oluşan (3 set-10 tekrar, 1-2 dakika dinlenme) antrenman programı uygulandı. Basketbolcular çalışma boyunca başka bir kuvvet antrenmanına veya benzer dirençli egzersiz tipine katılmadılar. Çalışmadan iki gün önce ön test ve çalışmanın bitiminden iki gün sonra son test ölçümleri alındı.

\section{Bulgular}

\begin{tabular}{|c|c|c|c|c|c|c|}
\hline Değişkenler & Gruplar & Testler & $\mathbf{n}$ & $\overline{\mathbf{X}}_{ \pm \mathbf{S s}}$ & $\mathbf{t}$ & $\mathbf{p}$ \\
\hline \multirow{4}{*}{$\begin{array}{l}\text { Boy uzunluğu } \\
\quad(\mathrm{cm})\end{array}$} & \multirow{2}{*}{ Çalışma } & Ön test & 7 & $164,42 \pm 6,02$ & \multirow{2}{*}{$-5,761$} & \multirow{2}{*}{0,001 ** } \\
\hline & & Son test & 7 & $166,55 \pm 5,69$ & & \\
\hline & \multirow{2}{*}{ Kontrol } & Ön test & 7 & $161,14 \pm 7,84$ & \multirow{2}{*}{$-7,322$} & \multirow{2}{*}{0,000 ** } \\
\hline & & Son test & 7 & $162,71 \pm 8,14$ & & \\
\hline \multirow{4}{*}{$\begin{array}{l}\text { Vücut ağırlığı } \\
(\mathrm{kg})\end{array}$} & \multirow{2}{*}{ Çalışma } & Ön test & 7 & $56,52 \pm 7,53$ & \multirow{2}{*}{$-2,218$} & \multirow{2}{*}{0,068} \\
\hline & & Son test & 7 & $58,22 \pm 7,91$ & & \\
\hline & \multirow{2}{*}{ Kontrol } & Ön test & 7 & $56,98 \pm 11,66$ & \multirow{2}{*}{$-3,072$} & \multirow{2}{*}{$0,022 *$} \\
\hline & & Son test & 7 & $58,98 \pm 11,54$ & & \\
\hline \multirow{4}{*}{ Şut atış (adet) } & \multirow{2}{*}{ Çalışma } & Ön test & 7 & $10,42 \pm 2,22$ & \multirow{2}{*}{$-0,171$} & \multirow{2}{*}{0,870} \\
\hline & & Son test & 7 & $10,71 \pm 4,53$ & & \\
\hline & \multirow{2}{*}{ Kontrol } & Ön test & 7 & $10,28 \pm 3,59$ & \multirow{2}{*}{1,564} & \multirow{2}{*}{0,169} \\
\hline & & Son test & 7 & $8,14 \pm 4,01$ & & \\
\hline \multirow{4}{*}{$\begin{array}{l}\text { Dikey sıçrama } \\
\qquad(\mathrm{cm})\end{array}$} & \multirow{2}{*}{ Çalışma } & Ön test & 7 & $35,28 \pm 6,01$ & & 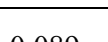 \\
\hline & & Son test & 7 & $37,57 \pm 6,34$ & $-2,027$ & 0,089 \\
\hline & Kontro1 & Ön test & 7 & $38,00 \pm 8,48$ & & \\
\hline & Kontrol & Son test & 7 & $38,42 \pm 8,46$ & $-0,430$ & 0,682 \\
\hline & & Ön test & 7 & $160,28 \pm 16,84$ & & \\
\hline Durarak uzun & Çalışma & Son test & 7 & $168,00 \pm 23,31$ & $-2,400$ & 0,053 \\
\hline atlama $(\mathrm{cm})$ & Kontrol & Ön test & 7 & $172,71 \pm 14,43$ & 0215 & 0827 \\
\hline & Kontrol & Son test & 7 & $170,00 \pm 15,39$ & 0,215 & 0,837 \\
\hline & & Ön test & 7 & $9,14 \pm 7,47$ & & \\
\hline & Çalışma & Son test & 7 & $12,57 \pm 7,56$ & $-4,076$ & $\mathbf{0 , 0 0 7 * *}$ \\
\hline (adet) & & Ön test & 7 & $9,42 \pm 8,63$ & & \\
\hline & Kontrol & Son test & 7 & $11,14 \pm 8,93$ & $-2,121$ & 0,078 \\
\hline & & Ön test & 7 & $18,42 \pm 1,71$ & & \\
\hline Mekik & Çalışma & Son test & 7 & $19,85 \pm 2,26$ & $-2,705$ & $0,035^{*}$ \\
\hline (adet) & & Ön test & 7 & $19,57 \pm 4,39$ & & \\
\hline & Kontrol & Son test & 7 & $20,71 \pm 2,56$ & $-1,486$ & 0,188 \\
\hline & & Ön test & 7 & $14,28 \pm 4,30$ & & \\
\hline Denge & Çalışma & Son test & 7 & $12,28 \pm 4,78$ & 0,907 & 0,399 \\
\hline (adet) & & Ön test & 7 & $14,42 \pm 2,63$ & & \\
\hline & Kontrol & Son test & 7 & $13,71 \pm 3,63$ & 0,658 & 0,535 \\
\hline & & Ön test & 7 & $20,12 \pm 7,78$ & 3000 & \\
\hline Esneklik & Çalışma & Son test & 7 & $21,28 \pm 7,15$ & $-3,900$ & $0,008^{* * *}$ \\
\hline$(\mathrm{cm})$ & & Ön test & 7 & $18,88 \pm 4,57$ & & \\
\hline & Kontrol & Son test & 7 & $19,51 \pm 6,03$ & $-0,730$ & 0,493 \\
\hline & & Ön test & 7 & $5,71 \pm 0,33$ & & \\
\hline & Çalışma & Son test & 7 & $5,53 \pm 0,30$ & 2,944 & $0,026 *$ \\
\hline (sn) & & Ön test & 7 & $5,70 \pm 0,31$ & & \\
\hline & Kontrol & Son test & 7 & $5,50 \pm 0,31$ & 6,094 & $0,001 * *$ \\
\hline & & Ön test & 7 & $7,07 \pm 0,63$ & 0585 & 0580 \\
\hline Saglik topu ile & Çalışma & Son test & 7 & $7,16 \pm 0,64$ & $-0,585$ & 0,580 \\
\hline atış & & Ön test & 7 & $6,96 \pm 1,62$ & & 0307 \\
\hline & Kontrol & Son test & 7 & $6,79 \pm 1,52$ & 0,912 & 0,397 \\
\hline
\end{tabular}

Tablo 1. Çalışma ve kontrol grubu değişkenlere ait ön test ve son test puanlarının grup içi karşılaştırılması $\mathbf{p}<0,05^{*} \quad \mathbf{p}<0,01^{* *}$

Tablo 1'de çalışma grubunda boy uzunluğu, şınav, mekik, esneklik ve sürat parametrelerinin ön test-son test puanlarının karşılaştırmasında anlamlı farklılık tespit edilmiştir $(p<0,05-p<0,01)$. 
Canlı, U. (2017). Basketbolculara terabant ile uygulanan kuvvet antrenmanlarının motorik beceriler ve şut performans1 üzerine etkisi. International Journal of Social Sciences and Education Research, 3(3), 857-869.

Kontrol grubunda boy uzunluğu, vücut ağırlığı ve sürat parametrelerinin grup içi karşılaştırmasında anlamlı farklılık tespit edilmiştir $(\mathrm{p}<0,05$ - $\mathrm{p}<0,01)$.

\begin{tabular}{|c|c|c|c|c|c|c|c|}
\hline Değisşkenler & Gruplar & $\mathbf{n}$ & Ölçümler & $\overline{\mathbf{X}} \pm \mathbf{S s}$ & $\begin{array}{c}\text { Fark } \\
\text { Son-ön test }\end{array}$ & $\mathbf{t}$ & $\mathbf{p}$ \\
\hline \multirow{4}{*}{$\begin{array}{l}\text { Boy } \\
\text { uzunluğu } \\
(\mathrm{cm})\end{array}$} & \multirow{2}{*}{ Çalışma } & 7 & Ön test & $164,42 \pm 6,02$ & & \multirow{4}{*}{$-1,304$} & \multirow{4}{*}{0,217} \\
\hline & & 7 & Son test & $166,55 \pm 5,69$ & $2,12 \pm 0,97$ & & \\
\hline & \multirow{2}{*}{ Kontrol } & 7 & Ön test & $161,14 \pm 7,84$ & \multirow{2}{*}{$1,57 \pm 0,56$} & & \\
\hline & & 7 & Son test & $162,71 \pm 8,14$ & & & \\
\hline \multirow{4}{*}{$\begin{array}{l}\text { Vücut } \\
\text { ağırlıı̆ } 1 \\
(\mathrm{~kg})\end{array}$} & \multirow{2}{*}{ Çalışma } & 7 & Ön test & $56,52 \pm 7,53$ & \multirow{2}{*}{$1,70 \pm 0,76$} & \multirow{4}{*}{0,298} & \multirow{4}{*}{0,771} \\
\hline & & 7 & Son test & $58,22 \pm 7,91$ & & & \\
\hline & \multirow{2}{*}{ Kontrol } & 7 & Ön test & $56,98 \pm 11,66$ & $200+172$ & & \\
\hline & & 7 & Son test & $58,98 \pm 11,54$ & $2,00 \pm 1, / 2$ & & \\
\hline \multirow{4}{*}{$\begin{array}{l}\text { Şut atış } \\
\text { (adet) }\end{array}$} & \multirow{2}{*}{ Çalışma } & 7 & Ön test & $10,42 \pm 2,22$ & \multirow{2}{*}{$0,28 \pm 4,42$} & \multirow{4}{*}{$-1,123$} & \multirow{4}{*}{0,283} \\
\hline & & 7 & Son test & $10,71 \pm 4,53$ & & & \\
\hline & \multirow{2}{*}{ Kontrol } & 7 & Ön test & $10,28 \pm 3,59$ & \multirow{2}{*}{$-2,14 \pm 3,62$} & & \\
\hline & & 7 & Son test & $8,14 \pm 4,01$ & & & \\
\hline \multirow{4}{*}{$\begin{array}{c}\text { Dikey } \\
\text { sıçrama } \\
(\mathrm{cm})\end{array}$} & \multirow{2}{*}{ Çalışma } & 7 & Ön test & $35,28 \pm 6,01$ & \multirow{2}{*}{$2,28 \pm 2,98$} & \multirow{4}{*}{$-1,234$} & \\
\hline & & 7 & Son test & $37,57 \pm 6,34$ & & & \\
\hline & & 7 & Ön test & $38,00 \pm 8,48$ & & & 0,241 \\
\hline & Kontrol & 7 & Son test & $38,42 \pm 8,46$ & $0,42 \pm 2,63$ & & \\
\hline & & 7 & Ön test & $160,28 \pm 16,84$ & & & \\
\hline $\begin{array}{c}\text { Durarak } \\
\text { nupnatlama }\end{array}$ & Çalışma & 7 & Son test & $168,00 \pm 23,31$ & $7,71 \pm 8,50$ & & \\
\hline uzun atlama & Kontrol & 7 & Ön test & $172,71 \pm 14,43$ & $271+844$ & $-2,303$ & $0,040^{*}$ \\
\hline & Kontrol & 7 & Son test & $170,00 \pm 15,39$ & $-2,71 \pm 8,44$ & & \\
\hline & & 7 & Ön test & $9,14 \pm 7,47$ & & & \\
\hline Şınav & Çalışma & 7 & Son test & $12,57 \pm 7,56$ & $3,42 \pm 2,22$ & & \\
\hline (adet) & Kontrol & 7 & Ön test & $9,42 \pm 8,63$ & $171+212$ & $-1,470$ & 0,167 \\
\hline & Kontrol & 7 & Son test & $11,14 \pm 8,93$ & $1,71 \pm 2,13$ & & \\
\hline & & 7 & Ön test & $18,42 \pm 1,71$ & & & \\
\hline Mekik & Çalışma & 7 & Son test & $19,85 \pm 2,26$ & $1,42 \pm 1,39$ & & \\
\hline (adet) & & 7 & Ön test & $19,57 \pm 4,39$ & & $-0,306$ & 0,765 \\
\hline & Kontrol & 7 & Son test & $20,71 \pm 2,56$ & $1,14 \pm 2,03$ & & \\
\hline & $C_{0} 1_{1 \mathrm{sm}}$ & 7 & Ön test & $14,28 \pm 4,30$ & $200+583$ & & \\
\hline & Çalışma & 7 & Son test & $12,28 \pm 4,78$ & $-2,00 \pm 5,83$ & & \\
\hline (adet) & & 7 & Ön test & $14,42 \pm 2,63$ & & 0,523 & 0,610 \\
\hline & Kontrol & 7 & Son test & $13,71 \pm 3,63$ & $-0,71 \pm 2,87$ & & \\
\hline & Colsmo & 7 & Ön test & $20,12 \pm 7,78$ & $115+078$ & & \\
\hline Esneklik & Çalışma & 7 & Son test & $21,28 \pm 7,15$ & $1,15 \pm 0,78$ & & \\
\hline$(\mathrm{cm})$ & & 7 & Ön test & $18,88 \pm 4,57$ & & $-0,580$ & 0,572 \\
\hline & Kontrol & 7 & Son test & $19,51 \pm 6,03$ & $0,62 \pm 2,27$ & & \\
\hline & & 7 & Ön test & $5,71 \pm 0,33$ & $-018+016$ & & \\
\hline Sürat & Çalışma & 7 & Son test & $5,53 \pm 0,30$ & & & 0700 \\
\hline$(\mathrm{sn})$ & & 7 & Ön test & $5,70 \pm 0,31$ & & $-0,262$ & 0,798 \\
\hline & Kontrol & 7 & Son test & $5,50 \pm 0,31$ & $-0,20 \pm 0,88$ & & \\
\hline & & 7 & Ön test & $7,07 \pm 0,63$ & & & \\
\hline Sağlik topu & Çalışma & 7 & Son test & $7,16 \pm 0,64$ & $0,08 \pm 0,38$ & 1078 & 0302 \\
\hline ile atış & Kontrol & 7 & Ön test & $6,96 \pm 1,62$ & $016+018$ & $-1,078$ & 0,302 \\
\hline & Kontrol & 7 & Son test & $6,79 \pm 1,52$ & $-0,16 \pm 0,48$ & & \\
\hline
\end{tabular}

Tablo 2. Çalışma ve kontrol grubu değişkenlere ait ön test - son test puan farklarının gruplar arası karşılaştırılması $\mathbf{p}<0,05^{*}$ 
Canl, U. (2017). The effect of strength trainings by using theraband on the motor skills and shooting performance of basketball players. International Journal of Social Sciences and Education Research, 3(3), 857-869.

Tablo 2'de çalışma ve kontrol grubuna ait durarak uzun atlama parametresinin son test-ön test puan farklarının karşılaştırılmasında anlamlı bir farklılık tespit edilmiştir $(\mathrm{p}<0,05)$. Diğer antropometrik ve biyomotorik verilerin son test-ön test puan farklarının gruplar arası karşılaştırılmasında anlamlı bir farklılık tespit edilmemiştir $(\mathrm{p}>0,05)$.

\section{Tartışma ve sonuç}

Araştırmamızda hem kontrol grubu hem de çalışma grubunun boy uzunluğu değerlerinde artış olduğu tespit edilmiş, bu artışın istatistiksel olarak ta anlamlı düzeyde olduğu belirlenmiştir. Araştırmaya katılan grupların boy uzunluğu değerlerinde anlamlı düzeyde artış olmasının temel nedeninin çocukların fiziksel olarak büyüme ve gelişme döneminde olmaları, diğer nedeninin ise fiziksel olarak aktif olmalarından kaynaklandığı düşünülmektedir. Yörükoğlu ve Koz (2007) çocukların boy uzunluğu ortalamalarındaki artışın doğumdan olgunlaşmaya kadar devam eden bir süreç olduğunu belirtmişlerdir. Yapılan birçok araştırmada çocuklarda spora katılım motor özellikleri ve fiziksel gelişimi desteklediği belirtilmiştir (M. Hekim ve Hekim, 2015). Vücut ağırlığ 1 değerleri her iki grupta da artış gösterdiği belirlenmiş ancak kontrol grubuna ait vücut ağırlığının ön test-son test puanlarının karşılaştırılmasında anlamlı bir farklılık tespit edilmiştir. Hamamioğlu ve Kaya (2008) 7-12 yaş aralığındaki basketbolcular üzerinde yaptığı çalışmada, çocukların ön test vücut ağırlık ortalamaların $33,50 \mathrm{~kg}$, son test ortalamalarını ise $34,96 \mathrm{~kg}$ olarak belirlemişlerdir. Buna göre basketbol antrenmanları ile sporcuların vücut ağırlıklarında artış meydana geldiği tespit edilmiştir. Bu araştırma sonucunda da çocuklarda vücut ağırlığı artışı olması bizim çalışma bulgularımızı destekler niteliktedir.

Araştırmamızda çalışma ve kontrol gruplarına ait sürat değerlerinin ön test-son test karşılaş̧tırılmasında istatistiksel olarak anlamlı farklılık tespit edilmiştir. Çalışma grubu 9 haftalık basketbol antrenmanı ve kuvvet çalışmaları sonucunda sürat değerini 5,71 saniyeden 5,53 saniyeye azaltmış, kontrol grubu ise 9 haftalık basketbol antrenmanları sonucunda sürat ortalamasını 5,70 saniyeden 5,50 saniyeye azaltmıştır. Müniroğlu, Şen ve Tanılkan (2000) çalışmalarında erkek çocukların $30 \mathrm{~m}$ sürat değerlerini 11 yaş grubunda 5,58 sn, 12 yaş grubunda 5,44 sn olarak tespit etmişlerdir. Kien ve Chiodo (2003) rekreasyon programlarına katılan 10-12 yaş ortaokul çocuklarının kendi yaş grubu rekreatif spor faaliyetlerine katılmayanlardan daha hılı olduklarını bulmuşlardır. Diallo, Dore, Duche ve Van Praagh (2001) 10-12 yaş çocuklara haftada 3 gün uyguladığ egzersiz sonucunda 20,30 ve $40 \mathrm{~m}$ sprint değerlerinde anlamlı farklılıklar bulmuşlardır.

Çalışma grubunun şınav ve mekik testleri puanlarının grup içi karşılaştırılmasında anlamlı fark tespit edilirken, kontrol grubunun şınav ve mekik değerlerinde artış olmasına rağmen istatistiksel olarak anlamlı bir fark tespit edilmemiştir. Selçuk'un (2013), 11-13 yaş grubu erkek yüzücülerde 12 haftalık terabant antrenmanının bazı motorik özellikler ile yüzme performansına etkileri adlı çalışmasında, 30 saniye mekik çekme ön test ve son test ortalamaları sırasıyla yüzme+terabant grubunda (YTG) 19,33 adet ve 33,91 adet, yüzme grubunda (YG) 19,58 adet ve 21,66 adettir. Yapılan istatistik sonucunda hem YTG hem de YG'nin ön-son test 30 saniye mekik çekme değerlerinde anlamlı bir gelişme olduğu gözlenmiştir. Benzer şekilde 30 saniye şınav çekme performansinda da hem YTG (ön test 23,41 adet, son test 34,41 adet) hem de YG'nin (ön test 26,50 adet, son test 28,25 adet) anlamlı gelişme gösterdiği tespit edilmiştir.

Çalışma grubunda esneklik parametresi açısından anlamlı bir farklılık tespit edilirken, kontrol grubunda esneklik değerinde artış olmasına rağmen istatistiksel olarak bir anlam ifade etmemektedir. Fiziksel aktivitenin esneklik üzerinde olumlu etkileri vardır. Ergenlik çağında esneklik üst 
Canlı, U. (2017). Basketbolculara terabant ile uygulanan kuvvet antrenmanlarının motorik beceriler ve şut performans1 üzerine etkisi. International Journal of Social Sciences and Education Research, 3(3), 857-869.

seviyeye çıkmaktadır (Hockey, 1993). Chatterjee ve Branyopadhyay (1993), 10-14 yaş grubu erkek öğrencilere uyguladıkları antrenman programı sonucunda deney grubunda \% 2,2'lik oranında esneklik artışı bulmaktadır. Farklı yöntemlerle yapılan kuvvet çalışmalarının esneklik performansı üzerine olumlu etkileri olduğunu gösteren çalışmalar bulunmaktadır (Ateş ve Ateşoğlu 2007; Faigenbaum vd., 2007).

Kontrol grubunda durarak uzun atlama ön test değeri $172,71 \mathrm{~cm}$, son test değeri $170,00 \mathrm{~cm}$ olarak tespit edilmiştir. Çalışma grubunda durarak uzun atlama ön test değeri $160,28 \mathrm{~cm}$, son test değeri 168,00 cm olarak tespit edilmiştir. İki grubunda grup içi karşılaştırılmalarında anlamlı bir fark tespit edilmezken, gruplar arası karşılaştırılmasında çalı̧̧ma grubu lehine istatistiksel olarak anlamlı bir farklılık tespit edilmiştir. Selçuk (2013) çalışmasında, sadece yüzme ve yüzme ile kuvvet antrenmanlarını beraber yapan çocukların durarak uzun atlama performanslarının anlamlı düzeyde geliştĭgi belirlenmiştir. Ayrıca kuvvet ve yüzme çalışmalarını birlikte yapan deney grubunun, sadece yüzme yapan gruba göre durarak uzun atlama performanslarının daha fazla geliştiği belirlenmiştir. Bu çalışma bizim çalışmamız ile paralellik göstermektedir.

Kontrol grubunun dikey sıçrama ön test ortalamas $38,00 \mathrm{~cm}$, son test ortalaması $38,42 \mathrm{~cm}$ 'dir. Çalışma grubunun ön test ortalaması $35,28 \mathrm{~cm}$, son test ortalaması $37,57 \mathrm{~cm}$ 'dir. Çalışma grubunda kontrol grubuna göre daha fazla gelişme olduğu gözlemlenmektedir. Ancak gerek grup içi gerekse gruplar arası karşıllaştırmada anlamlı bir farklılık tespit edilmemiştir. Bavlı (2009) adölesan basketbolcular üzerinde yaptığı çalışmada, 12 haftalık pliometrik egzersizlerin sporcuların dikey sıçrama performanslarının ön test-son test puanları karşılaştırıldığında istatistiksel anlamda fark olduğu belirlenmiştir. Saygın (2003) aktivite düzeyi hafif olan çocuklar ile orta şiddetli olanlar arasında dikey sıçrama açısından anlamlı farklılık bulmuştur. Hoffman, Stavsky ve Falk (1995) hareket eğitimi alan 12-14 yaş çocuklarda, dikey sıçrama parametrelerinde anlamlı farklılık bulduklarını belirtmişlerdir.

Sağlık topu ile atış ortalamalarında 9 haftalık periyod sonunda kontrol grubunun değerlerinde azalma belirlenirken çalışma grubunun değerlerinde ise artış tespit edilmiş̧ir. Ancak istatistiksel olarak grup içi ve gruplar arası anlamlı bir farklılık tespit edilmemiştir. Ateş ve Ateşoğlu'nun (2007) pliometrik antrenmanın 16-18 yaş grubu erkek futbolcuların üst ve alt ekstremite kuvvet parametreleri üzerine etkisi adlı çalışmasında, sağ ve sol el itme, taç atışı ve göğüsten atma kuvvetlerinde gruplar arasında anlamlı farklılıklar tespit edilmiştir. Atma gibi hareketlerde vücudun birçok kas grubu örneğin sırt, omuz, bacak ve kol kasları gibi aktif olarak hareketin başarılı bir şekilde gerçekleşmesini sağlarlar. 12-14 yaş grubu çocuklar üzerinde yapılan çalışmada 16 haftalık futbol beceri antrenmanlarının mekik çekme ve bacak kuvveti performansını arttırdığı belirlenmiştir (İri, Sevinç ve Süel, 2009). Benzer şekilde 8-14 yaş grubunda bulunan kız ve erkek çocuklarında yaz spor okuluna katılımın sırt kuvvetini geliştirdiği tespit edilmiştir (Ağaoğlu, Taşmektepligil, Aksoy ve Hazar, 2008).

Kontrol ve çalışma grubunun statik denge ortalamalarında artış tespit edilmiş bu artışında çalışma grubunda daha yüksek değerlerde olduğu belirlenmiştir. Ancak grup içi ve gruplar arası karşılaştırmalarda anlamlı bir fark bulunamamıştır. Bilindiği gibi kuvvet, denge özelliklerini etkileyen bir faktördür ve iyi bir bacak kuvveti dengenin de iyi olmasını beraberinde getirmektedir (Muratlı, Kalyoncu ve Şahin, 2007). Yüksel vd. (2016) basketbolculara uyguladıkları core antrenmanların dinamik denge üzerindeki etkilerinde deney grubunun denge yeteneği değerleri hem sağ ayakta hem de sol ayakta kontrol grubuna göre gelişim göstermiştir. McLeod, Armstrong, Miller ve Sauers (2009)'da yaptıkları çalışmada, 6 haftalık denge antrenmanlarının genç lisesi 
Canl, U. (2017). The effect of strength trainings by using theraband on the motor skills and shooting performance of basketball players. International Journal of Social Sciences and Education Research, 3(3), 857-869.

basketbolcu bayanlarda Yıldız Denge Testi ön test ve son test sonuçları arasında anlamlı değişimlere neden olduğu verisini ortaya koymuştur.

Şut performansı açısından grupları değerlendirdiğimizde kontrol grubunun şut performansında düşüş tespit edilirken çalışma grubunda ise az oranlarda da olsa bir artış söz konusudur. Grup içi ve gruplar arası karşılaştırmalarda istatistiksel olarak anlamlı bir farklılık tespit edilmemiştir. Wooten (2003) çalışmasında basketbolda şut isabetinin bir kısmının sporcunun kendine güveniyle diğer kısmının ise özel olarak dizayn edilmiş şut antrenmanları ile birlikte şuta yardımcı olan kas gruplarının gücünün ve esnekliğinin artırılması ile sağlanabileceğini belirtmiştir. Gürpınar, Sözeri, Tuncel ve Erol (2009) 16-17 erkek basketbolcular üzerinde yaptığı çalışmasında, deney grubu kuvvet antrenmanları ile birlikte şut antrenmanı yaparken kontrol grubu ise sadece şut antrenmanı yapmıştır. Elde edilen bulgulara göre her iki grubunda şut isabet sayılarında ve yüzdelerinde anlamlı artışlar ortaya çıktığı belirtilmiştir. İlk testte şut yüzdesi \% 46 olan deney grubunun antrenman dönemi bittiğindeki şut yüzdesi \%56'nın üzerine çıkmıştır. İsabetli atılan şut sayısında ise \%23'lük bir artış gözlenmiştir. Çalışma grubumuzun küçük yaş gruplarından oluşması sebebiyle henüz kendilerine özgü atış tekniklerinin tam oluşmaması, testlerin yapıldığı gün konsantrasyon ve motivasyonlarının değişiklik göstermesi şut performanslarında herhangi bir farkın oluşmamasında etkili olmuş olabilir.

Sonuç olarak, basketbol antrenmanı yapmış olan kontrol grubumuzun dikey sıçrama, şınav, mekik, denge, esneklik ve sürat ortalamalarında artış olduğu belirlenmiş, sadece sürat değerinin grup içi karşılaştırılmasında anlamlı bir farklılık tespit edilmiştir. Terabant kullanılarak kuvvet antrenmanı ve basketbol antrenmanı yaptırılan çalışma grubumuzun şut performansları ve tüm biyomotorik değerlerinde artışlar belirlenmiştir. Çalışma grubunun şınav, mekik, esneklik ve sürat değişkenlerinin grup içi karşılaştırılmasında anlamlı fark tespit edilirken, durarak uzun atlama ortalamalarında gruplar arası anlamlı farklılık tespit edilmiştir. Çalışma grubunun şut atış değerlerinde düşük düzeyde artış olmasına rağmen istatistiksel olarak anlam ifade etmemektedir. Şut performansının değerlendirilmesi aşamasında, çalışma ve kontrol grubunun müsabakalardaki şut isabet yüzdeleri de değerlendirilmeye katılarak çalışmanın gerçek ortama yansıması tam olarak ortaya konulabilir. Sezon içerisinde yaptığımız basketbol antrenmanı ile birleştirilmiş kuvvet çalışmaları adölesan dönem içerisinde bulunan basketbolcuların motorik ve şut performanslarına katkı sağladığg ortaya konulmuştur. Bu yaş grupları ile çalışan basketbol antrenörlerine bu antrenman yöntemini sezon içerisinde kullanmaları önerilebilir.

\section{Kaynakça}

Acar, M. F. (2000). Kuramsal Boyutlarıyla Antrenman Bilimi El Kitabı. İzmir: Meta Basım.

Ağaoğlu, S. A., Taşmektepligil, M. Y., Aksoy, S., \& Hazar, F. (2008). Yaz spor okullarına katılan gençlerin yaş gruplarına göre fiziksel ve teknik gelişimlerinin analizi. Spormetre Beden Eğitimi ve Spor Bilimleri Dergisi, 6, 159-66.

Ates, M., \& Atesoğlu, U. (2007). Pliometrik antrenmanın 16-18 yaş grubu erkek futbolcuların üst ve alt ekstremite kuvvet parametreleri üzerine etkisi. Spormetre Beden Ĕgitimi ve SporBilimleri Dergisi, 5(1), 21-28.

Bavlı, Ö. (2009). Havuz pliometrik egzersizleri ile alan pliometrik egzersizlerinin adolesan dönem basketbolcuların biyomotorik ve yapısal özelliklerine etkisi. Yayımlanmamış Doktora Tezi, Çukurova Üniversitesi, Sağlık Bilimleri Enstitüsü, Adana. https://tez.yok.gov.tr sayfasından erişilmiştir. 
Canlı, U. (2017). Basketbolculara terabant ile uygulanan kuvvet antrenmanlarının motorik beceriler ve şut performans1 üzerine etkisi. International Journal of Social Sciences and Education Research, 3(3), 857-869.

Canl1, U. (2017). The effect of somatotype profiles of adolescent basketball players on biomotoric characteristics and ability. IOSR Journal of Sports and Physical Education, 4(1), 61-64.

Chatterjee, S., \& Branyopadhyay, A. (1993). Effect of continuous slow speed running for 12 weeks 10-14 years old Indian boys. Br J Sports Med, 27(3), 179-185.

Diallo, O., Dore, E., Duche, P., \& Van Praagh, E. (2001). Effects of plyometric training followed by a reduced training programme on physical performance in prebubescent soccer players. J Sports Med Phys Fitness, 41(3), 342-348.

Faigenbaum, A. D., McFarland, J, Keiper, F. B., Tevlin, W., Ratamess, N. A., Kang, J., \& Hoffman, J. R. (2007). Effects of a short-term plyometric and resistance training program on fitness performance in boys age 12 to 15 years. Journal of Sports Science and Medicine, 6, 519-525.

Gürpınar, B., Sözeri, B., Tuncel, F., \& Erol, E. (2009). 16-17 yaş grubu erkek basketbolcularda çabuk kuvvet antrenmanın sıçrayarak şut yüzdesine etkisinin incelenmesi. Gazi Beden Eğitimi ve Spor Bilimleri Dergisi, 3, 3-12.

Hamamioğlu, Ö., \& Kaya, Y. (2008). Basketbol sporunun 7-12 yaşlarındaki erkek çocuklarındaki boy-kilo ve vücut yağ oranına etkisi. Niğde Üniversitesi Beden Ĕgitimi ve Spor Bilimleri Dergisi, 2(3), 182-192.

Hekim, M., \& Hekim, H. (2015). Overview to strenght development and strenght trainings in children. The Journal of Current Pediatrics, 13, 110-115.

Hockey, V. (1993). The Pathway to Healthful Living. U.S.A: Mosby Publishing.

Hoffman, J. R., Stavsky, H., \& Falk, B. (1995). The effect of water restriction anaerobic power and vertical jumping height in basketball players. Int J Sport Med, 16(4), 214-218.

İri, R., Sevinç, H., \& Süel, E. (2009). 12-14 yaş grubu çocuklara uygulanan futbol beceri antrenmanın temel motorik özelliklere etkisi. Uluslararası Ínsan Bilimleri Dergisi, 6, 123-31.

Kamar, A. (2008). Sporda Yetenek Beceri ve Performans Testleri. Ankara: Nobel Yayınları.

Kien, C. L., \& Chiodo, A. R. (2003). Physical activity in middle school-aged children participating in a school-based recreation program. Arch Pediatr Adolesc Med, 157(8), 811-815.

Mackenzie, B. (2005). 101 Performance Evaluation Test. London: Electric Word Plc. erişim http://shahroodut.ac.ir/fa/download.php?id=1111125195

McLeod, T. C. V., Armstrong, T., Miller, M., \& Sauers, J. L. (2009) Balance improvements in female high school basketball players after a 6 week neuromuscular-training program. Journal of Sport Rehabilitation, $18,465-481$.

Muratl1, S. (1998). Çocuk ve Spor. Ankara: Bağırgan Yayınevi.

Muratl1, S., Kalyoncu, O., \& Şahin, G. (2007). Antreman ve Müsabaka. İstanbul: Ladin Matbaacılık.

Müniroğlu, S., Şen, P., \& Tanılkan, K. (2000). Ankara'daki 12-14 yaş grubu kız erkek uzun ve kısa mesafe yüzücülerin dikey sıçrama derecelerin incelenmesi. Marmara Üniversitesi Spor Araştırmaları Dergisi, 4(1), 21-32.

Özer, M. K. (2009). Kinantropometri, Sporda Morfolojik Planlama (2. Bask1). İstanbul: Nobel Yayınları.

Page, P., \& Ellenbecker, T. (2005). Strenght Band Training. Champaign: Human Kinetics Publisher.

Pekel, H. A. (2007). Atletizmde yetenek aramasına bağlı olarak 10-12 yaş grubu çocuklarda bazı değişkenler üzerinde normatif çalışma (Ankara ili örneği). Yayımlanmamış Doktora Tezi, Gazi Üniversitesi, Sağlık Bilimleri Enstitüsü, Ankara. https://tez.yok.gov.tr sayfasından erişilmiştir. 
Canl, U. (2017). The effect of strength trainings by using theraband on the motor skills and shooting performance of basketball players. International Journal of Social Sciences and Education Research, 3(3), 857-869.

Pojskic, H., Separovic, V., \& Uzicanin, E. (2011). Reliability and factorial validity of basketball shooting accuracy tests. Sport Scientific And Practical Aspects, 8(1), 25-32.

Saygın, Ö. (2003). 10-12 yaş çocukların fiziksel aktivite düzeyleri ile fiziksel uygunluklarının incelenmesi. Yayımlanmamış Doktora Tezi, Marmara Üniversitesi, Sağlık Bilimleri Enstitüsü, İstanbul. https://tez.yok.gov.tr sayfasından erişilmiştir.

Selçuk, H. (2013). 11-13 yaş grubu erkek yüzücülerde 12 haftalık terabant antrenmanının bazı motorik özellikler ile yüzme performansına etkileri. Yayımlanmamış Yüksek Lisans Tezi, Selçuk Üniversitesi, Sağlık Bilimleri Enstitüsü, Konya. https://tez.yok.gov.tr sayfasından erişilmişstir.

Sevim, Y. (1988). Hentbolde kombine kuvvet antrenmanlarının sıçrama ve atış kuvveti üzerinde etkisi. Yayımlanmamış doktora tezi, Gazi Üniversitesi, Sosyal Bilimler Enstitüsü, Ankara.

Tamer, K. (2000). Sporda Fiziksel-Fizyolojik Performansın Ölçülmesi ve Değerlendirilmesi. Ankara: Bağırgan.

Yolcu, S. Ö. (2010). Direnç makinelerine karşın lastik bant antrenmanlarının puberte öncesi çocuklarda kassal kuvvete etkileri. Yayımlanmamış Yüksek Lisans Tezi, Ege Üniversitesi, Sağlık Bilimleri Enstitüsü, İzmir.

Yörükoğlu, U., \& Koz, M. (2007). Spor okulu çalışmaları ile basketbol antrenmanlarının 10-13 yaş grubu erkek çocukların fiziksel, fizyolojik ve antropometrik özelliklerine etkisi. Spormetre Beden Eğitimi ve Spor Bilimleri Dergisi, 5 (2), 79-83.

Yüksel, O., Akkoyunlu, Y., Karavelioğlu, M. B., Harmancı, H., Kayhan, M., \& Koç, H. (2016). Basketbolcularda core alt ekstremite kuvveti antrenmanlarının dinamik denge ve şut isabeti üzerine etkisi. Marmara Üniversitesi Spor Bilimleri Dergisi, 1(1), 51-61. doi: 10.22396/sbd.2016.5

Wooten, M. (2003). Coaching Basketball Successfully (2nd Edition). Champaign: Human Kinetics Publisher.

Zatsiorsky, V. M., \& Kraemer, W. J. (2006). Science and Practice of Strenght Training (2.Bask1). Champaign: Human Kinetics Publisher. 
Canlı, U. (2017). Basketbolculara terabant ile uygulanan kuvvet antrenmanlarının motorik beceriler ve şut performansı üzerine etkisi. International Journal of Social Sciences and Education Research, 3(3), 857-869.

\section{Extended abstract in English}

The strength, which can be considered as the most important of the biomotor skills, is one of the most important factors for performing the sportive performance in children and young people. Properly selected equipment and arranged exercises are expected to have positive effects on the development of children's strength.

There are a several methods of developing strength. These methods are provided by various equipment and machine besides their body weight. One of these tools used to improve strength is elastic band (theraband). The greatest feature of elastic bands is the increase in resistance as they get stretched. Trainers prefer these bands because of their low cost and portability. These bands are also used for many purposes. The use of bands by sportsmen in rehabilitation exercises after being injured is very common (Page ve Ellenbecker, 2005).

In studies aiming to develop strength with the use of theraband in children, it has been determined that regular theraband exercises induce the development of strength (Yolcu, 2010). The therabands may contribute to the development of strength, as well as to the development of other motoric features. Because the therabands have the features of multi-directional and feeling the applied motions at every angle. It is also another advantage of the therabands that they can be used in all age groups (Page ve Ellenbecker, 2005).

The aim of this study is to examine the effects of theraband trainings which has been applied for 9 weeks on the shooting performance and some biomotor skills of the basketball players. 14 male basketball players who make matches at local children's league have participated in the research voluntarily. The average of the participants' ages is 12.79 years and the average period of their sportive history is 3.32 years. The participating basketball players have been separated into two groups of 7 persons as control and study groups according to their pre-test scores. During the 9-week period, an average of 3.09 basketball training sessions have been performed each week with both the control and the study groups. In addition, the study group has performed strength trainings using theraband combined with basketball training. Before and after the 9 -week training program, pre-test and post-tests have been applied to the participants by measuring their body height and weight, $30 \mathrm{~m}$ sprint, $2 \mathrm{~kg}$ medicine ball throw, standing long jump, $30 \mathrm{sec}$. push up, 30 sec. sit up, flexibility, static balance, vertical jumping and basketball shooting tests. While Shapiro-Wilk Test has been used to test normality, paired-samples t-test has been used for intragroup statistics and independent-samples t-test has been used for inter-group statistics.

According to the intra-group comparisons made at the end of the study, statistically significant $(\mathrm{p}<0.05)$ differences have been determined in body height, flexibility, sprint and push up test scores of the study group. On the other hand, statistically significant $(\mathrm{p}<0.05)$ differences have been determined in body height, sprint and body weight scores of the control group according to the intra-group comparisons. No significant change has been determined in shooting performance of the players in both of the groups according to intra-group and inter-group statistics $(p<0.05)$. A significant difference has been found only at standing long jump test values in favor of the 
Canl, U. (2017). The effect of strength trainings by using theraband on the motor skills and shooting performance of basketball players. International Journal of Social Sciences and Education Research, 3(3), 857-869.

study group $(\mathrm{p}<0.05)$ according to the inter-group comparisons of the the pre-test-post-test scores (difference test).

As a result, it was determined that our control group with basketball training had an increase in vertical jump, push-up, shuttle, balance, flexibility and speed average, and only a significant difference was found in the comparison of the speed value within the group. In our study group where strength training and basketball training were performed using theraband, increases in shot performances and all biometrical values were determined. While there was a significant difference detected in the comparison of the push-up, shuttle, flexibility and speed variables within the group of the study group, a significant difference was found between the groups in the long jump average. The study group does not make any statistical significance even though there is a slight increase in the shot values. During the evaluation process of the shot performance, the reflection to actual environment of the work can be fully demonstrated by participating in the evaluation of the shooting hit percentage of the study and the control group in competitions. It is revealed that the combined strength work with the basketball training we did in the season contributes to the motoric and shooting performances of the basketball players in the adolescence period. It may be advisable for basketball trainers working with these age groups to use this training method during the season. 